\title{
25 Research Square \\ High-fat diet impairs muscle function and increases the risk of environmental heatstroke in mice
}

\author{
Matteo Serano \\ CAST, Univ. G. D’Annunzio of Chieti-Pescara \\ Cecilia Paolini \\ CAST, Univ. G. D’Annunzio of Chieti-Pescara \\ Antonio Michelucci \\ CAST, Univ. G. D'Annunzio of Chieti-Pescara \\ Laura Pietrangelo \\ CAST, Univ. G. D'Annunzio of Chieti-Pescara \\ Flavia Alessandra Guarnier \\ Londrina State University \\ Feliciano Protasi ( $\square$ feliciano.protasi@unich.it ) \\ CAST, Univ. G. D'Annunzio of Chieti-Pescara
}

\section{Research Article}

Keywords: excitation-contraction coupling, heat stroke, high-fat diet.

Posted Date: March 8th, 2022

DOI: https://doi.org/10.21203/rs.3.rs-1392730/v1

License: (c) (i) This work is licensed under a Creative Commons Attribution 4.0 International License.

Read Full License 


\section{Abstract}

Background. Environmental heat-stroke (HS) is a life-threatening response often triggered by a hot and humid weather. HS is characterized by an abnormal increase in body temperature $\left(>40^{\circ} \mathrm{C}\right)$ causing dysfunction of organs, central nervous system, and that may end in death. Several lines of evidence indicate that environmental HS is caused by excessive heat production in skeletal muscle, which in turn is the result of abnormal $\mathrm{Ca}^{2+}$ leak from the sarcoplasmic reticulum (SR) and excessive production of oxidative species of oxygen and nitrogen (ROS and NOS).

Methods. As high fat diet is known to increase oxidative stress, the objective of the present study was to investigate the effects of 3 months of high-fat diet (HFD) on HS susceptibility of wild type (WT) mice. HS susceptibility was tested in an environmental chamber where 4 months old mice (adult) were exposed to heat stress $\left(41^{\circ} \mathrm{C}\right.$ for $\left.1 \mathrm{hr}\right)$.

Results. In comparison with mice fed with a regular diet, mice subjected to 3 months of HFD showed: a) increased body weight and accumulation of adipose tissue; b) elevated oxidative stress in both EDL and Soleus muscles (assessed by western blot of 3-NT levels and of expression of antioxidant enzymes such as SODs and Catalase) ; c) increased heat generation and oxygen consumption during exposure to environmental heat stress (oxygen consumption was assessed by indirect calorimetry) ; and finally d) enhanced sensitivity to both temperature and caffeine of isolated EDL and Soleus muscles during in vitro contracture test (IVCT), i.e. the gold standard procedure used to verify in-vitro HS susceptibility.

Conclusions. The data collected suggest that HFD predisposes WT mice to HS, possibly as a result of elevated myoplasmic $\mathrm{Ca}^{2+}$ (indirectly assessed by IVCT) and increased oxidative stress (directly assessed by WB). These results could in principle have implications for the development of guidelines regarding food intake during periods of intense environmental heat.

\section{Introduction}

Heat stroke (HS) is life-threatening response caused by exposure to environmental heat often combined to high humidity (environmental HS). HSs are characterized by a rapid increase in core body temperature (above $40^{\circ} \mathrm{C}$ ), culminating in dysfunction of organs and of central nervous system [1].

Global warming has become reason of concern also for human health due to the dramatic rise in mortality rate during heat waves $[2,3]$. Heat waves are periods of abnormally and uncomfortably hot and usually humid weather [4] and, according to the American Meteorological Society glossary, a heat wave corresponds to a period of three consecutive days during which the maximum temperature is above the threshold of $32.2^{\circ} \mathrm{C}$.

The impact of heat waves on human health, especially in urban areas, is very well documented in literature (hundreds of scientific reports) and, surprisingly, these reports indicate that more than $90 \%$ of human deaths in natural hazards are caused by hot weather [5]. Some specific heat waves are very well 
documented: the 2003 France heat wave was accompanied by an excess mortality of exceptional magnitude: 14,947 excess deaths in the period of August 4-18 [6]. Interestingly mortality returned to its normal level starting on August 19th. Just a few months ago, dozens of people have died in Canada in an unprecedented heat wave that has smashed temperature records (close to $50^{\circ} \mathrm{C}$ ). And these are only a few examples of a very long list $[7,8]$. Even if several factors may contribute to sudden death in high environmental temperatures, the most common cause of death attributable to heat is dehydration, heat cramps and exhaustion, and hyperthermia, i.e. in one word heat stroke (HS) [9].

However, while the correlation between environmental heat and increased mortality is now clear, the mechanisms mediating multi-organ damage, the drugs to be used in emergency situations, and finally life habits that may prevent or reduce triggering of HS in hot weather are still debated.

In humans, there is syndrome characterized by an abnormal increase in body temperature known as malignant hyperthermia susceptibility (MHS). MHS is a genetic life-threatening pharmacogenetic response triggered by halogenated anesthetics such as isoflurane or halothane [10-12], which share many pathophysiological features with HS: rhabdomyolysis, increase in serum creatine kinase, hyperkalemia, tachycardia, metabolic acidosis and unbridled rise in body temperature[1,13]. Patients who have experienced heat stress, which is the perceived discomfort that precedes HS [1] have higher incidence of being positive in vitro contracture tests (IVCT), the gold-standard test used to determine MHS of patients. IVCT measures the contractile sensitivity of a muscle biopsy to triggering agents such as caffeine and halothane [14-16].

Correlation between $\mathrm{MH}$ and HS (hypothesized in humans) have been already demonstrated in animal models carrying specific gene mutations: a) swine that carry a point mutation in the skeletal muscle ryanodine receptor type-1 (RyR1) trigger MH episodes in response to halothane administration, but also during exposure to either heat or emotional/physical stress[17, 18]; b) knock-in mice that carry gain-offunction mutations in the RYR1 gene that are causative of MHS in humans (R163C and Y522S) are susceptible to lethal overheating crises when exposed to either halogenated anesthetics or elevated temperature [19, 20]; finally c) mice that lack the protein calsequestrin-1 (CASQ1-null) also exhibit lethal anesthetic- and heat-induced hyperthermic episodes [21-24]. Studies from our group and others indicates that rhabdomyolysis of skeletal muscle fibers during MHS/HS crisis is the final result of complex cascade of events starting from excessive $\mathrm{Ca}^{2+}$ leak from RyR1 mediated by oxidative stress and consequent nitrosylation of RyR1 [25]. In support of this view, in Michelucci et al. (2015) we demonstrated that antioxidants protect CASQ1-null mice from anesthetic- and heat-induced lethal crisis. In addition: a) moderate aerobic training and administration of estrogens reduced the mortality rate of CASQ1-null mice during heat stress reducing oxidative stress and mitochondrial damage [22, 26].

While correlation between MHS and HS has been demonstrated in animals carrying specific gene mutations, which factors and how lifestyle habits may either increase or diminish the risk of the normal population to HS in challenging environmental conditions remain to be determined. According to WHO (World Health Organization) the prevalence of obesity nearly tripled between 1975 and 2016. The 
fundamental cause of obesity and overweight is the energy imbalance between calories consumed and calories expended, meaning increased intake of energy-dense foods that are high in fat and sugars combined with reduced physical inactivity. Interestingly, excessive consumption of calories, especially those related to lipids and fatty acids, has been associated to increased inflammatory biomarkers[27] and oxidative stress levels. Diet rich in fat may induce oxidative stress, potentially through the up-regulated expression of genes for ROS production and through mitochondrial respiratory chain overload [28]. As we have demonstrated that mice models susceptible to HS crises display high level of oxidative stress[22, $23,25,26,29]$ in the present study, we tested whether high-fat diet administrated to WT mice may predispose to environmental HS crisis.

\section{Methods}

\section{Animals and experimental design.}

All experiments were conducted according to the Directive of the European Union and were approved by the Animal Ethical Committees of the University of Chieti-Pescara. Male C57bl/ 6 mice of 1 month of age were randomly assigned to two experimental groups: Control (Ctrl) fed a regular diet and high-fat diet (HFD) group. In the control diet 10\% of metabolized energy was from fat (C 1090-10, Altromin, Germany), whereas HFD mice were fed with obesity-inducing diet (in which $70 \%$ of metabolized energy was from fat) (C 1090-70, Altromin, Germany). The complete composition of both Ctrl and HFD diets is detailed in Table S1. Once assigned to the two experimental groups, mice were housed in microisolator cages at $20^{\circ} \mathrm{C}$ in a 12-h light/dark cycle and provided free access exclusively to the respective diets and water (2 animals/cage). Food intake was registered three times a week. The weight of mice was registered at the beginning and at the end of the diet treatment (at 1 and 4 months of age).

Before experiments, animals were killed by cervical dislocation as approved by the local University Committee on Animal Resources (1202/2020-PR).

\section{In vivo experiments.}

- Grip strength test. Grip strength of both Ctrl and HFD groups was measured holding mice by the tail and lowering them to a metal grating connected to the shaft of a Shimpo Fgv 0.5X force transducer (Metrotec Group, Spain). Once the mouse had firmly grabbed the grating, a gentle pull was exerted on the tail [29]. Measurements of peak force generated by each mouse using fore limbs were repeated three times with appropriate intervals (30s) to avoid fatigue. Average peak force values were normalized to body weight measured immediately before each experiment.

- Indirect Calorimetry. At 4 months of age, mice of both e Ctrl and HFD groups were placed individually in chambers for measurement of oxygen consumption and allowed to adapt for $24 \mathrm{hrs}$. After adaptation, the volume of oxygen consumption $\left(\mathrm{VO}_{2}\right)$ and of carbon dioxide production $\left(\mathrm{VCO}_{2}\right)$ were registered for 24 hrs using a Oxylet-Pro indirect calorimeter system (Pan Lab, Spain). The analysis of the respiratory 
quotient (RQ) and of the energy expenditure were performed using the Metabolism software provided with the instrument (Pan Lab, Spain) [30].

- Heat Stress (HS) protocol and core temperature recording. In order to determine the sensitivity of mice to heat, in the day after the assessment of oxygen consumption by indirect calorimetry (see above), mice were subjected to the heat stress (HS) protocol. Briefly, mice were first placed individually in the same chambers used for indirect calorimetry and then chambers were placed inside an environmental chamber where the temperature was kept at $41^{\circ} \mathrm{C}$ for $1 \mathrm{hr}$ (two mice - one of each experimental group - were tested simultaneously). During the HS protocol the respiratory gas volumes were registered every $6 \mathrm{~min}$ for $1 \mathrm{hr}$. Core (using a four channels thermometer TM-946, XS instruments, Italy) and skin (using a CW364, RS Components, Italy) temperatures were registered just before and after exposure to HS test in each mouse.

\section{Experiments after animals were euthanized.}

- In vitro contracture test (IVCT). Extensor digitorum longus (EDL) muscles were dissected from both experimental groups (Ctrl and HFD) and placed in a dish containing Krebs-Hanseleit solution ( $\mathrm{NaCl} 137$ $\mathrm{mM}, \mathrm{KCl} 5 \mathrm{mM}, \mathrm{MgSO}_{4} 1 \mathrm{mM}, \mathrm{CaCl}_{2} 2 \mathrm{mM}, \mathrm{NaH}_{2} \mathrm{PO}_{4} 1.2 \mathrm{mM}$, HEPES $0.5 \mathrm{mM}$, and glucose $10 \mathrm{mM}$ ). EDL were then tied with fine silk sutures at each end, and mounted vertically between two platinum electrodes, attached to a servomotor and force transducer (model 1200A, Aurora Scientific, Canada). Once mounted, muscles were immersed in a chamber filled with Krebs-Hanseleit solution, and before starting the experimental protocol, stimulation level and optimal muscle length $\left(L_{0}\right)$ were determined using a series of $80 \mathrm{~Hz}$-tetani in order to optimize muscle length to generate maximal force $\left(F_{0}\right)$. After optimization of the stimulation conditions, EDL muscles were subjected to a force-frequency protocol based on a series of train pulses of 500 ms duration each from 1 to $250 \mathrm{~Hz}$ in EDL and from 1 to $200 \mathrm{~Hz}$ in Soleus. Specific force $\left(\mathrm{mN} / \mathrm{mm}^{2}\right)$ was calculated by normalizing the absolute force $(\mathrm{mN})$ to the cross-sectional area (CSA, $\mathrm{mm}^{2}$ ) obtained as the following formula: muscle wet weight $(\mathrm{mg}) / \mathrm{L}_{0}(\mathrm{~mm}) * 1.06\left(\mathrm{mg} / \mathrm{mm}^{3}\right)$. In order to determine caffeine sensitivity of resting tension, muscles were continuously stimulated with electrical stimulation $(0.2 \mathrm{~s}$ at $0.2 \mathrm{~Hz}$ applied every $5 \mathrm{~s}$; duty cycle, 0.04$)$ at $30^{\circ} \mathrm{C}$ and exposed to increasing caffeine concentrations every $3 \mathrm{~min}$, as follows: $0,2,4,6,8,10,14,18,22$ and $26 \mathrm{mM}$. On the other hand, to evaluate the development of contractures induced by increasing temperature, EDL muscles were electrically stimulated with a series of consecutive twitches $(1 \mathrm{~ms}$ duration, $0.2 \mathrm{~Hz}$ for each twitch, applied every 5 seconds) and exposed to steps of increasing temperature, each of $2^{\circ} \mathrm{C}$ every $5 \mathrm{~min}$ (from $30^{\circ} \mathrm{C}$ to $44^{\circ} \mathrm{C}$ ). Muscle force was continuously recorded using a dynamic muscle control software and analyzed using dynamic muscle analysis software (Aurora Scientific, Canada).

- Blood analysis. Immediately after HS, $100 \mu \mathrm{L}$ of blood were collected from mice's tail vein, then transferred to $1.5 \mathrm{~mL}$ micro tubes, centrifuged at $3000 \mathrm{xg}$ for $15 \mathrm{~min}$ at $4^{\circ} \mathrm{C}$ for plasma separation, and stored in $200 \mu \mathrm{L}$ micro tubes at $-20^{\circ} \mathrm{C}$ until use. Levels of potassium (Potassium turbidimetric assay kit, myBioSource, USA), calcium (Calcium colorimetric assay kit, Sigma-Aldrich, USA) and creatine kinase activity (Creatine kinase activity assay kit, Sigma-Aldrich, USA) were quantified in plasma samples, following manufacturer's instructions and expressed in $\mathrm{mmol} / \mathrm{L}$, units/L and $\mathrm{nmol} / \mu \mathrm{L}$ respectively. 
- Assessment of rhabdomyolysis. Immediately after the HS protocol, EDL muscles were carefully dissected, fixed at room temperature with $3.5 \%$ glutaraldehyde in $0.1 \mathrm{M} \mathrm{NaCaCo}$ buffer (pH 7.4), and kept at $4^{\circ} \mathrm{C}$ in fixative until further use. Fixed muscles were then postfixed in $2 \% 0$ sO4 in the same buffer for 2 $\mathrm{h}$, then block-stained in uranyl acetate replacements. After dehydration, specimens were embedded in an epoxy resin (Epon 812; Electron Microscopy Sciences, USA) and embedded as previously described [31]. Semi-thin $(800 \mathrm{~nm})$ sections were cut with a Leica Ultracut R Microtome (Leica Microsystems, Austria) using a Diatome diamond knife (Diatome, Switzerland). Sections were stained in a solution containing $1 \%$ Toludine blue $\mathrm{O}$ and $1 \%$ Sodium Borate Tetra in distilled water for $3 \mathrm{~min}$ on a hot plate at $55-60^{\circ} \mathrm{C}$. After washing and drying, sections were mounted with DPX mounting medium for histology (SigmaAldrich, Milan, Italy) and viewed by using a Leica DMLB light-microscope (Leica Microsystems, Vienna, Austria) connected to a Leica DFC450 camera (Leica Microsystem, Vienna, Austria). Muscles fibers were then classified in i) apparently normal, ii) fibers with unstructured cores, and iii) fibers with contracture cores [29]. Data were shown as percentage of all evaluated fibers.

- Oxidative stress. EDL muscles were rapidly dissected from Ctrl and HFD mice, and quickly frozen in liquid nitrogen until use. At the appropriate time, muscles were homogenized in RIPA buffer (TRIS HCl $50 \mathrm{mM} \mathrm{pH} 7.4$, Triton-X 1\%, Deoxycholate 0.25\%, NaCl 150mM, SDS 3\%, EDTA 1mM, Protease inhibitors $2.5 \%$ ) using a mechanical homogenizer and then centrifuged for $15 \mathrm{~min}$ at $900 \mathrm{x} \mathrm{g}$ at $4^{\circ} \mathrm{C}$. The supernatant was collected, and protein concentrations were determined spectrophotometrically using a BCA quantification kit (ThermoFisher scientific, USA). Equal amounts of total protein $(20 \mu \mathrm{g})$ were resolved in 12\% (SOD1 and SOD2), or in 10\% (catalase and 3-NT) sodium dodecyl sulfate polyacrylamide gel electrophoresis and transferred to nitrocellulose membranes. Blots were then blocked with $5 \%$ non-fat dry milk (EuroClone, Italy) in TBS-T $0.1 \%$ for $1 \mathrm{hr}$. Membranes were probed with primary antibody diluted in $5 \%$ non-fat dry milk in TBS-T overnight at $4^{\circ} \mathrm{C}$, as follows: anti-superoxide dismutase type-1 (SOD-1) antibody (rabbit polyclonal 1:1000, Santa Cruz Biotechnology Inc., USA), anti-superoxide dismutase type2 (SOD-2) antibody (rabbit polyclonal 1:1000, Santa Cruz Biotechnology, Inc., USA), anti-catalase antibody (rabbit polyclonal 1:1000, Santa Cruz Biotechnology Inc., USA), anti-3-NT antibody (mouse monoclonal, 1:500 Merck Millipore, Italy) and anti-glyceraldehyde-3-phosphate dehydrogenase antibody (GAPDH) (mouse monoclonal, 1:10000 OriGene Technologies Inc., USA) that was used as housekeeping.

After incubation with primary antibodies, membranes were washed with TBS-T and then incubated with secondary antibodies (1:10000, horseradish peroxidase-conjugated, Merck Millipore, USA) diluted in 5\% non-fat dry milk in TBS-T for $1 \mathrm{hr}$ at RT and washed in TBS-T. The different proteins were detected by enhanced chemiluminescent liquid (Perkin-Elmer, USA), and their amount on the immunoblots were quantified using the imaging system Alliance Mini 4 with Alliance 1D MAX software (UVItec Cambridge, UK). Membranes incubated with anti-3-NT antibody were stripped by TRIS/SDS buffer with 2mercaptoethanol. After blocking, membranes were incubated with anti-glyceraldehyde-3-phosphate dehydrogenase antibody (GAPDH) (mouse monoclonal, 1:10000 OriGene Technologies Inc., USA) for normalization to protein content of each band.

\section{Statistical analysis.}


The statistical analysis is reported in the legend of each figure. Data are shown as mean \pm SEM. In all cases, differences were considered statistically significant at $p<0.05$. Unpaired Student's t-tests and were performed using two-way ANOVA tests were performed using GraphPad Prism 6 software.

\section{Results}

1. HFD induced metabolic modifications in adult WT mice. We monitored food intake, body weight gain, and evaluated the percentage of adipose tissue in control and HFD mice during the 3 months of diets (Fig. 1). No significant differences were found between the amount of chow consumed by the two experimental groups of mice (Fig. 1A). However, even though the amount of food ingested was approximately the same, the HFD group of mice showed an increase in body weight gain in the 3 months of diets $(15.65 \pm 0.44 \mathrm{gr})$ much greater than the Ctrl group $(4.73 \pm 0.94 \mathrm{gr}, \mathrm{p}<0.01)$ (Fig. 1B).

We also quantified the amount of body fat dissecting the adipose tissue from each animal, as shown in Fig. $1 \mathrm{C}$ and $\mathrm{D}$ : this analysis indicated that most of the excessive weight in HFD mice was accumulated in body fat: $11.28 \pm 0.63 \%$ in Ctrl vs. $20.68 \pm 1.30 \%$ in HFD (Fig. 1E).

We then used indirect calorimetry to evaluate whether the HFD diet modified the oxygen consumption and metabolic rate of mice (Fig. 2). The results shown in Fig. 2 indicates that HFD induced a significant reduction in $\mathrm{VO}_{2}$ consumption at rest, compared to Ctrl: on the average a decrease of $25 \%$ of $\mathrm{VO}_{2}$ consumption in both light and dark cycles (Fig. 2A). In line with these results, also the respiratory quotient $\left(\mathrm{RQ}=\mathrm{VCO}_{2}\right.$ produced $/ \mathrm{VO}_{2}$ consumed) was different (Fig. $\left.2 \mathrm{~B}\right)$. Figure $2 \mathrm{~B}$ shows that Ctrl mice, at rest, maintain their RQ curve between 0.8 and 0.9 in both light and dark cycles. On the other hand, the consumption of HFD mice over 3 months switched the RQ to constant values very close to 0.75 , which indicates a predominantly lipid-oriented metabolism compared to Ctrl. The results above mentioned were reinforced by curves of baseline energy expenditure (or BEE) (Fig. 2C), showing an average decrease of $20 \%$ in HFD mice during all circadian cycle when compared to Ctrl.

2. HFD caused muscle dysfunction and oxidative stress. In vivo muscle function was evaluated measuring grip strength (Fig. 3A): HFD mice displayed significant reduction in normalized grip strength $(\mathrm{mN} / \mathrm{g})(\sim 31 \%$ of reduction compared to $\mathrm{Ctrl})$.

We then determined the functional output of isolated muscles, evaluating the force/frequency response of isolated muscles in an ex vivo set up (see Methods). EDL muscles dissected from HFD mice showed a reduction in specific force curve starting from $75 \mathrm{~Hz}$ ( 20\% of reduction) (Fig. 3B). However, when relative force normalized to $250 \mathrm{~Hz}$ was assayed, no statistical differences were shown between the two groups (Fig. 3C). Interestingly, we found comparable results even in Soleus muscles: muscles from HFD mice showed significant reduction in specific force starting at $\sim 50 \mathrm{~Hz}(\sim 14 \%$ of reduction; Fig. S1 A). Though, when relative force was normalized to $250 \mathrm{~Hz}$ in EDL (Fig. 3B) and to $200 \mathrm{~Hz}$ in Soleus (Fig. S1 B), no statistical differences were shown between Ctrl and HFD. These data suggest that the difference found in specific force is likely not due to a switch in fiber type composition. 
As excessive production of reactive oxygen and nitrogen species (ROS/RNS) has been proposed to be a key step in the cascade of molecular events that leads to HS crises in MH susceptible mice $[21,23,25,26$, 32], we investigated the presence of markers of oxidative stress and damage in EDL and Soleus homogenates from our two experimental groups. First, we assayed by western blot (WB) the amount of 3nitrotyrosine (3-NT) (Fig. 4A), a product of nitration of tyrosine residues of proteins mediated by RNS [33]. EDL from HFD contains levels of 3-NT 60\% higher when compared to Ctrl. In addition, we evaluated levels of: i) copper/zinc superoxide dismutase (SOD1) (Fig. 4B) and manganese superoxide dismutase (SOD2) (Fig. 4C), the two main intracellular isoforms of a class of enzymes that catalyze the dismutation of $\mathrm{O}_{2}{ }^{-}$ into $\mathrm{O}_{2}$ and $\mathrm{H}_{2} \mathrm{O}_{2}$, the first step in the elimination of ROS generated primarily in mitochondria [34]; and ii) Catalase (Fig. 4D), one of the most important antioxidant enzymes that catalyzes the decomposition of $\mathrm{H}_{2} \mathrm{O}_{2}$ to $\mathrm{H}_{2} \mathrm{O}$ and $\mathrm{O}_{2}$ and that represents an important antioxidant defense for skeletal muscle, acting immediately after the action of SOD1 and SOD2 [35]. In HFD mice the level of these enzymes was increased respectively of 28\% (SOD1), 31\% (SOD2), and 167\% (Catalase) when compared to Ctrl.

Similar results were collected in Soleus muscle, a predominantly slow twitch muscle (Fig. S2): 2.0-fold increasing in 3-NT (Fig. S2 A), and 40\% (Fig. S2 B) and 26\% (Fig. S2 C) increase in SOD-1 and SOD-2, respectively. Finally, also Catalase showed increased levels in the HFD group: $41 \%$ when compared with Ctrl (Fig. S2 D).

3. HFD induced increased metabolic rate during Heat Stress. We exposed mice to a heat stress protocol $\left(41^{\circ} \mathrm{C}\right.$ for $\left.1 \mathrm{hr}\right)$ using a custom-made environmental chamber in which we could control temperature and humidity. While exposed to HS, mice were kept inside metabolic chambers (see Methods) to evaluate $\mathrm{VO}_{2}$ consumption and BEE by indirect calorimetry.

The HFD significantly increases the $\mathrm{VO}_{2}$ consumed during heat stress (Fig. $5 \mathrm{~A}$ ): the difference between initial $\left(T_{0}\right)$ and final $\left(T_{f}\right)$ values of $\mathrm{VO}_{2}$ consumption reaches $5 \mathrm{~mL} / \mathrm{min} / \mathrm{kg}^{0.75} \mathrm{in} \mathrm{Ctrl}$, while in HFD this difference was about $7 \mathrm{~mL} / \mathrm{min} / \mathrm{kg}^{0.75}$ in some mice $(\mathrm{p}<0.05$ in the whole curve, in the comparison HFD $\mathrm{x}$ Ctrl). Likewise, under heat stress also energy expenditure of HFD mice was increased by $~ 13 \%$ when compared to Ctrl (Fig. 5B). To verify if the increased metabolism was accompanied by changes in body temperature, we registered body and skin temperature of each mouse before and after the heat stress protocol. Significant differences were found both in core (Fig. 5C) and skin (Fig. 5D) temperatures after the heat stress protocol. Core body temperature, assayed by rectal temperature, increased both in Ctrl and HFD mice, but more in the latter: $35.38 \pm 0.06^{\circ} \mathrm{C}$ to $39.20 \pm 0.13^{\circ} \mathrm{C}$ in $\mathrm{Ctrl}(\Delta \mathrm{T}=3.82) ; 35.97 \pm 0.38^{\circ} \mathrm{C}$ to $40.53 \pm 0.26^{\circ} \mathrm{C}$ in HFD $(\Delta T=4.56)$. Measurements of skin temperature was higher in HFD mice already before the heat stress protocol $\left(31.50 \pm 0.24^{\circ} \mathrm{C}\right.$ in Ctrl vs. $32.13 \pm 0.14^{\circ} \mathrm{C}$ in HFD), increasing during the heat stress protocol to $33.43 \pm 0.44^{\circ} \mathrm{C}$ vs. $35.12 \pm 0.45^{\circ} \mathrm{C}$ in Ctrl and HFD, respectively.

4. HFD induced hypersensitivity of muscles to IVCT (and increased blood levels of markers of muscle damage). In vitro contracture test (IVCT) is the gold standard technique to evaluate the oversensitivity of muscles to heat[36, 37]. We performed an in vitro heat stress protocol, based on exposure of isolated 
muscles to increasing steps of temperature of $2^{\circ} \mathrm{C}$ each (Fig. 6A). When exposed to this protocol, EDL muscles excised from HFD mice showed a significant increase in basal tension starting from $\sim 38^{\circ} \mathrm{C}$ (Fig. 6A), that at $44^{\circ} \mathrm{C}$ became $\sim 30 \%$ higher in EDL from HFD compared with Ctrl. We then performed a classic caffeine-dose response experiment, mimicking the in vitro contracture test (IVCT) that is used in humans to test MH susceptibility [36,37]. Caffeine is a potent agonist of RyR1 that triggers release of $\mathrm{Ca}^{2+}$ from the SR: MH susceptible patients usually display a lower threshold of response to caffeine [38, 39]. In Fig. 6B, the basal tension in EDL muscles of HFD mice starts to be significantly higher than Ctrl starting at $18 \mathrm{mM}$ of caffeine. At the end of the experiments basal tension at $26 \mathrm{mM}$ of caffeine was higher in HFD of $\sim 14 \%$, compared to that recorded in Ctrl. We performed similar experiment also in Soleus muscles, detecting a difference in heat sensitivity also in this muscle: increase in basal tension compared to Ctrl starting at $\sim 40^{\circ} \mathrm{C}$ (Fig. S1 C), with a relative basal tension at the end of the experiment $\left(44^{\circ} \mathrm{C}\right)$ which was $~ 15 \%$ higher in Soleus from HFD compared to Ctrl.

Environmental HS may be accompanied by muscle damage and rhabdomyolysis, which can be assessed by blood and histological analyses. In mice exposed to the heat stress protocol ( $41^{\circ} \mathrm{C}$ for $\left.1 \mathrm{hr}\right)$ (Fig. 7 ): plasma levels of $\mathrm{K}^{+}(7.51 \pm 0.32 \mathrm{mmol} / \mathrm{L} ; \mathrm{Fig} .7 \mathrm{~A}), \mathrm{Ca}^{2+}(1.60 \pm 0.09 \mathrm{nmol} / \mathrm{L} ;$ Fig. 7B) and total creatine kinase (CK) (161.26 $\pm 20.04 \mathrm{U} / \mathrm{L}$; Fig. 7C) from HFD were all significantly increased in comparison to Ctrl $(6.31 \pm 0.33 \mathrm{mmol} / \mathrm{L} ; 1.35 \pm 0.05 \mathrm{nmol} / \mathrm{L}$; and $99.42 \pm 16.00 \mathrm{U} / \mathrm{L}$, respectively).

We finally quantified in histological sections, the percentage of EDL fibers that were affected by structural damage after heat stress (Fig. S3). EDL fibers were classified in 3 main groups that presented the following typical features: i) fibers with no apparent damage (Fig. S3 A); ii) fibers with unstructured cores (Fig. S3 B); and 3) fibers with contracture cores (Fig. S3 C). No detectable differences were registered between the two experimental groups: $20.66 \%$ of fibers with damage (unstructured + contracture cores) in Ctrl (total $n=121$ ) vs. $17.98 \%$ in HFD (total $n=89$ ).

\section{Discussion}

- State of the Art. In the latest years, global warming has become reason of concern for human health due to the dramatic rise in mortality rate during heat waves $[3,40]$. An increase in mortality in these periods has been associated to cardiovascular, respiratory and kidney diseases [41-44], to nervous systems dysfunction [45-47], and also to diabetes [44, 48].

Even if several factors may contribute the death in high environmental temperatures (age, pre-existing disease, urban residence, isolation, poverty, air pollution), the most common cause of death attributable to heat is dehydration, heat cramps, exhaustion, and hyperthermia, i.e. in one word heatstroke (HS) [9]. Our group have contributed in the last decade to study the molecular mechanisms underlying HS: excessive production of oxidative stress in skeletal muscle fibers seems to play an important role in these event[25]. 
-Main Findings. We hypothesized that high fat diet (HFD) may be a factor of risk for HS, because consumption of excessive amount of fats has been already associated to increase in oxidative stress [28]. The results collected in the present study indicated that 3 months of HFD were able to produce anatomical changes: increase in body weight and in total adipose tissue mass, though, without significant modifications in the amount of food ingested (Fig. 1). These changes were accompanied by a decrease in the level of energy spent for basal metabolism when compared to Ctrl (Fig. 2), by muscle and dysfunction (Fig. 3 and Fig. S1) and, finally, by increased levels of oxidative stress in muscle, both fast and slow twitch (Fig. 4 and Fig. S2). While basal energy expenditure (BEE) was reduced in standard housing conditions (Fig. 2), during HS mice fed with HFD showed a significantly increased $\mathrm{VO}_{2}$ consumption and increased body temperature (Fig. 5). These changes were accompanied by isolated muscle being more prone to develop contracture during IVCT in response to temperature and caffeine (Fig. 6) and by increased circulating levels of markers of muscle damage (Fig. 7).

- The effects of HFD: changes in basal metabolism, oxidative stress, and muscle dysfunction. Increase in body weight and increase in adipose tissue in mice fed HFD were accompanied by significant modifications in metabolism: lower metabolic rate and a shift toward the use of lipids, when compared to Ctrl, as shown by the decreased RQ (Fig. 2). Indeed, RQ gives information about which is the main substrate oxidized during mitochondrial respiration, i.e. the relative amount of glucose, lipids, or proteins used to produce energy (Even and Nadkarni 2012). RQ is different for carbohydrate, lipid, and proteins, because the $\mathrm{VCO}_{2} / \mathrm{VO}_{2}$ ratio is higher in proteins and glucose than in lipids: a ratio between 0.7 and 0.8 indicates the prevalent use of lipids and proteins as substrates, whereas a ratio above 0.8 indicates increasing use of carbohydrates as the main source of energy. The consumption of HFD mice over 3 months switched to $R Q$ values very close to 0.75 , lower than controls (Fig. 3 ). Another parameter that was evaluated is basal energy expenditure or BEE, which indicates the energy required for the normal functioning of cells and organs. It is calculated based on $\mathrm{VO}_{2}$ consumption registered by indirect calorimetry and it is proportional to it, being both values representative of total metabolism [49]. HFD administration caused a decrease in both $\mathrm{VO}_{2}$ consumption and $\mathrm{BEE}$ sufficient to lower total metabolic rate at rest of about 25\% compared to Ctrl mice (Fig. 2). This is consistent with data published in humans showing a decreased basal energy expenditure in individuals chronically fed a diet containing $40 \%$ more fats compared to a control diet $[49,50]$, although some genetic individual variability was found [51]. In our mice, the metabolic changes caused by HFD were accompanied by oxidative stress and dysfunction of skeletal muscle, the organ responsible for the overgeneration of heat during HS. Levels of oxidative stress were significantly elevated both in fast and slow twitch muscle in HFD mice when compared to Ctrl (Fig. 4 and Fig. S2). In the past 15 years we collected strong evidence that oxidative stress is the key event underlying the increased susceptibility to heat, at least in animal models. The mechanistic hypothesis is that excessive production of ROS and RNS during exposure to heat would cause a dangerous feed-forward cycle that involves RyR1 S-nitrosylation, which, in turn, increases the opening probability of the channel (Durham et al. 2008; Protasi et al. 2009; Michelucci et al. 2015; Michelucci et al. 2017). The consequent excessive release of $\mathrm{Ca}^{2+}$ from the SR would finally promote contracture and rhabdomyolysis of skeletal muscle fibers that underlie $\mathrm{MH} / \mathrm{HS}$ reactions. 
Skeletal muscle dysfunction was assessed by in vivo and in vitro experiments. Decreased values in grip strength test and reduction in force production both in EDL and Soleus muscle when subjected to in vitro stimulation protocols were detected (Fig. 3 and Fig. S1). The decrease in force may be caused by several factors, one of them being oxidative stress itself, as ROS and NOS are known to cause oxidative damage to proteins and membranes and to alter their function [35, 52]. For instance, a physiological condition in which generation of force is impaired and accompanied by excessive oxidative stress is ageing [31, 5356].

- The effects of HFD: increased susceptibility to heat stress. While the basal metabolism of HFD mice was reduced compared to Ctrl in normal housing conditions, when we subjected mice to environmental heat stress $\left(1 \mathrm{hr}\right.$ at $41^{\circ} \mathrm{C}$ ) both $\mathrm{BEE}$ and $\mathrm{VO}_{2}$ consumption were surprisingly increased in HFD compared to Ctrl (Fig. 5). Increased metabolism was also accompanied by increase in core and skin temperatures during the heat stress protocol (Fig. 5). The greater increase in body temperature could be the result of two factors: 1. the increase in oxygen consumption and metabolism; 2 . the increased amount of adipose tissue that, being an insulating tissue, could limit the dissipation of heat.

The classic clinical features of $\mathrm{MH}$ and HS crises are: hypermetabolism, increased internal temperature, increased circulating levels of potassium $\left(\mathrm{K}^{+}\right)$and creatine kinase (CK), and rhabdomyolysis $[1,14]$. Here, in addition to increased metabolism and excessive rise in body temperature (discussed above; Fig. 5), we also measured circulating factors that may suggest muscle damage detecting increased levels of $\mathrm{K}^{+}$, $\mathrm{Ca}^{2+}$, and CK (Fig. 7). Histological analyses, though, revealed no significant difference in the percentage of damaged EDL fibers between Ctrl and HFD mice (Fig. S3). The increase of blood markers of muscle damage without a visible change in histology suggests that damage, where present, is still mild.

Finally, because muscles from MH mice display high susceptibility to develop contracture when isolated muscles are subjected to increasing concentration of caffeine and heat [21, 25], here we also tested muscles with IVCT: EDL, but also Soleus muscles from HFD mice developed higher basal tension compared to Ctrl in response to both heat and caffeine (Fig. 6 and Fig. S1). Increased generation of tension indicate higher levels of myoplasmic $\mathrm{Ca}^{2+}$ concentration, which is a hallmark of $\mathrm{MH} / \mathrm{HS}$ crises.

- Final remarks. Our study indicates that 3-months of HFD may predispose C57bl/6 mice to HS susceptibility. HS susceptibility may result from increased oxidative stress and consequent excessive $\mathrm{Ca}^{2+}$ leak from the SR, similar mechanisms underlie also MHS in humans.

As global warming is increasing the frequency of heat waves, which may be dangerous for human health especially in urban areas, a deeper understanding of the mechanisms causing HS is urgent. This study points out that there are factors, in this case bad food habits, that may increase the risk of healthy people to undergo hyperthermic crises when exposed to high environmental temperature. The results collected in this study may have implications for the development of guidelines regarding food intake during heatwaves. Further studies should be carried out to investigate other risk factors and test the efficacy of treatments in preventing or blocking HS. 


\section{Abbreviations}

calcium release unit: $\mathrm{CRU}$

electron microscopy: EM

excitation-contraction coupling: EC coupling

heat stroke: HS

malignant hyperthermia susceptibility: MHS

ryanodine receptor: RyR

sarcoplasmic reticulum: SR

transverse tubule: TT

high-fat diet: HFD

\section{Declarations}

Ethics approval and consent to participate: All experiments were conducted according to the Directive of the European Union and were approved by the Animal Ethical Committees of the University of ChietiPescara and Italian Ministry of Health (1202/2020-PR).

Consent for publication: Not applicable.

Availability of data and materials: The datasets used and/or analyzed during the current study are available from the corresponding author on reasonable request.

Competing interests: The authors declare that they have no competing interests.

Funding: This work was supported by grants: 1) GGP19231 from Italian Telethon ONLUS; 2) subcontract of AR059646 to F.P. from National Institutes of Health (USA); 3) PRIN \#2015ZZR4W3 to F.P. from Italian Ministry of University and Research.

Authors' contributions: F.A.G. and F.P. conceived and directed the study. M.S., A.M., and C.P. performed the experimental work and data analysis. In detail, M.S. performed experiments and data analysis of Figs. 15, 7 and S3. C.P. performed histological experiments of Fig. S1. Functional experiments in Figs. 5, 6 and S3 were performed by M.S. and A.M. Finally, M.S., L.P., F.A.G, and F.P. wrote and edited the manuscript.

Acknowledgements: Not applicable. 


\section{References}

1. Bouchama A, Knochel JP. Heat stroke. N Engl J Med [Internet]. 2002;346:1978-88. Available from: http://www.ncbi.nlm.nih.gov/pubmed/12075060

2. Gaffen DJ, Ross RJ. Increased summertime heat stress in the US. Nature. 1998;396:529-30.

3. Basu R, Samet JM. Relation between elevated ambient temperature and mortality: a review of the epidemiologic evidence. Epidemiol Rev [Internet]. 2002;24:190-202. Available from: http://www.ncbi.nlm.nih.gov/pubmed/12762092

4. Rossati A. Global Warming and Its Health Impact. The international journal of occupational and environmental medicine. 2017;8:7-20.

5. Posey C. Heat Wave. Weatherwise. 1980;33:112-6.

6. Poumadère M, Mays C, le Mer S, Blong R. The 2003 heat wave in France: dangerous climate change here and now. Risk analysis: an official publication of the Society for Risk Analysis. 2005;25:148394.

7. Lim CL. Fundamental Concepts of Human Thermoregulation and Adaptation to Heat: A Review in the Context of Global Warming. International Journal of Environmental Research and Public Health. 2020;17:7795.

8. Matthews TKR, Wilby RL, Murphy C. Communicating the deadly consequences of global warming for human heat stress. Proceedings of the National Academy of Sciences of the United States of America. 2017;114:3861-6.

9. Yeo TP. Heat stroke: a comprehensive review. AACN clinical issues. 15:280-93.

10. Jurkat-Rott K, McCarthy T, Lehmann-Horn F. Genetics and pathogenesis of malignant hyperthermia. Muscle \& nerve. 2000;23:4-17.

11. Lichtman AD, Oribabor $C$. Malignant hyperthermia following systemic rewarming after hypothermic cardiopulmonary bypass. Anesthesia and analgesia. 2006;102:372-5.

12. Treves S, Anderson AA, Ducreux S, Divet A, Bleunven C, Grasso C, et al. Ryanodine receptor 1 mutations, dysregulation of calcium homeostasis and neuromuscular disorders. Neuromuscular disorders: NMD. 2005;15:577-87.

13. Ducreux S, Zorzato F, Müller C, Sewry C, Muntoni F, Quinlivan R, et al. Effect of ryanodine receptor mutations on interleukin- 6 release and intracellular calcium homeostasis in human myotubes from malignant hyperthermia-susceptible individuals and patients affected by central core disease. The Journal of biological chemistry. 2004;279:43838-46.

14. Hopkins PM. Malignant hyperthermia: advances in clinical management and diagnosis. $\mathrm{Br} \mathrm{J}$ Anaesth [Internet]. 2000;85:118-28. Available from: http://www.ncbi.nlm.nih.gov/pubmed/10928000

15. Hackl W, Winkler M, Mauritz W, Sporn P, Steinbereithner K. Muscle biopsy for diagnosis of malignant hyperthermia susceptibility in two patients with severe exercise-induced myolysis. British journal of anaesthesia. 1991;66:138-40. 
16. Bendahan D, Kozak-Ribbens G, Confort-Gouny S, Ghattas B, Figarella-Branger D, Aubert M, et al. A noninvasive investigation of muscle energetics supports similarities between exertional heat stroke and malignant hyperthermia. Anesthesia and analgesia. 2001;93:683-9.

17. Jones EW, Nelson TE, Anderson IL, Kerr DD, Burnap TK. Malignant hyperthermia of swine. Anesthesiology [Internet]. 1972;36:42-51. Available from: http://www.ncbi.nlm.nih.gov/pubmed/5006985

18. Nelson TE, Jones EW, Venable JH, Kerr DD. Malignant hyperthermia of Poland China swine: studies of a myogenic etiology. Anesthesiology [Internet]. 1972;36:52-6. Available from: http://www.ncbi.nlm.nih.gov/pubmed/5006987

19. Chelu MG, Goonasekera SA, Durham WJ, Tang W, Lueck JD, Riehl J, et al. Heat- and anesthesiainduced malignant hyperthermia in an RyR1 knock-in mouse. FASEB J [Internet]. 2006;20:329-30. Available from: http://www.ncbi.nlm.nih.gov/pubmed/16284304

20. Yang T, Riehl J, Esteve E, Matthaei KI, Goth S, Allen PD, et al. Pharmacologic and functional characterization of malignant hyperthermia in the R163C RyR1 knock-in mouse. Anesthesiology [Internet]. 2006;105:1164-75. Available from: http://www.ncbi.nlm.nih.gov/pubmed/17122579

21. Dainese M, Quarta M, Lyfenko AD, Paolini C, Canato M, Reggiani C, et al. Anesthetic- and heatinduced sudden death in calsequestrin-1-knockout mice. FASEB J [Internet]. 2009;23:1710-20. Available from: http://www.ncbi.nlm.nih.gov/pubmed/19237502

22. Guarnier FA, Michelucci A, Serano M, Pietrangelo L, Pecorai C, Boncompagni S, et al. Aerobic Training Prevents Heatstrokes in Calsequestrin-1 Knockout Mice by Reducing Oxidative Stress. Oxid Med Cell Longev [Internet]. 2018;2018:4652480. Available from:

http://www.ncbi.nlm.nih.gov/pubmed/29849896

23. Michelucci A, Paolini C, Canato M, Wei-Lapierre L, Pietrangelo L, de Marco A, et al. Antioxidants protect calsequestrin-1 knockout mice from halothane- and heat-induced sudden death. Anesthesiology [Internet]. 2015;123:603-17. Available from: http://www.ncbi.nlm.nih.gov/pubmed/26132720

24. Protasi F, Paolini C, Dainese M. Calsequestrin-1: a new candidate gene for malignant hyperthermia and exertional/environmental heat stroke. J Physiol [Internet]. 2009;587:3095-100. Available from: http://www.ncbi.nlm.nih.gov/pubmed/19417098

25. Durham WJ, Aracena-Parks P, Long C, Rossi AE, Goonasekera SA, Boncompagni S, et al. RyR1 Snitrosylation underlies environmental heat stroke and sudden death in Y522S RyR1 knockin mice. Cell [Internet]. 2008;133:53-65. Available from: http://www.ncbi.nlm.nih.gov/pubmed/18394989

26. Michelucci A, Boncompagni S, Canato M, Reggiani C, Protasi F. Estrogens Protect Calsequestrin-1 Knockout Mice from Lethal Hyperthermic Episodes by Reducing Oxidative Stress in Muscle. Oxid Med Cell Longev [Internet]. 2017;2017:6936897. Available from: http://www.ncbi.nlm.nih.gov/pubmed/29062464

27. Milajerdi A, Saneei P, Larijani B, Esmaillzadeh A. The effect of dietary glycemic index and glycemic load on inflammatory biomarkers: a systematic review and meta-analysis of randomized clinical 
trials. Am J Clin Nutr [Internet]. 2018;107:593-606. Available from:

http://www.ncbi.nlm.nih.gov/pubmed/29635487

28. Matsuzawa-Nagata N, Takamura T, Ando H, Nakamura S, Kurita S, Misu H, et al. Increased oxidative stress precedes the onset of high-fat diet-induced insulin resistance and obesity. Metabolism [Internet]. 2008;57:1071-7. Available from: http://www.ncbi.nlm.nih.gov/pubmed/18640384

29. Paolini C, Quarta M, Wei-LaPierre L, Michelucci A, Nori A, Reggiani C, et al. Oxidative stress, mitochondrial damage, and cores in muscle from calsequestrin-1 knockout mice. Skelet Muscle [Internet]. 2015;5:10. Available from: http://www.ncbi.nlm.nih.gov/pubmed/26075051

30. Alberts $\mathrm{P}$, Johansson BG, McArthur RA. Characterization of energy expenditure in rodents by indirect calorimetry. Curr Protoc Neurosci [Internet]. 2006;Chap. 9:Unit9 23D. Available from: http://www.ncbi.nlm.nih.gov/pubmed/18428652

31. Pietrangelo L, D’Incecco A, Ainbinder A, Michelucci A, Kern H, Dirksen RT, et al. Age-dependent uncoupling of mitochondria from $\mathrm{Ca} 2(+)$ release units in skeletal muscle. Oncotarget [Internet]. 2015;6:35358-71. Available from: http://www.ncbi.nlm.nih.gov/pubmed/26485763

32. Michelucci A, Paolini C, Boncompagni S, Canato M, Reggiani C, Protasi F. Strenuous exercise triggers a life-threatening response in mice susceptible to malignant hyperthermia. FASEB $J$ [Internet]. 2017;31:3649-62. Available from: http://www.ncbi.nlm.nih.gov/pubmed/28465322

33. Ogino K, Wang DH. Biomarkers of oxidative/nitrosative stress: an approach to disease prevention. Acta Med Okayama [Internet]. 2007;61:181-9. Available from: http://www.ncbi.nlm.nih.gov/pubmed/17726507

34. McCord JM, Fridovich I. The utility of superoxide dismutase in studying free radical reactions. I. Radicals generated by the interaction of sulfite, dimethyl sulfoxide, and oxygen. J Biol Chem [Internet]. 1969;244:6056-63. Available from: http://www.ncbi.nlm.nih.gov/pubmed/4981789

35. Powers SK, Ji LL, Kavazis AN, Jackson MJ. Reactive oxygen species: impact on skeletal muscle. Compr Physiol [Internet]. 2011;1:941-69. Available from: http://www.ncbi.nlm.nih.gov/pubmed/23737208

36. EMH group. A protocol for the investigation of Malignant Hyperthermia $(\mathrm{MH})$ susceptibility. British Journal of Anaesthesia. 1984;56:1267-9.

37. Larach MG. Standardization of the caffeine halothane muscle contracture test. North American Malignant Hyperthermia Group. Anesth Analg [Internet]. 1989;69:511-5. Available from: http://www.ncbi.nlm.nih.gov/pubmed/2675676

38. Lopez JR, Linares N, Pessah IN, Allen PD. Enhanced response to caffeine and 4-chloro-m-cresol in malignant hyperthermia-susceptible muscle is related in part to chronically elevated resting [Ca2+]i. Am J Physiol Cell Physiol [Internet]. 2005;288:C606-12. Available from: http://www.ncbi.nlm.nih.gov/pubmed/15537710

39. Tegazzin V, Scutari E, Treves S, Zorzato F. Chlorocresol, an additive to commercial succinylcholine, induces contracture of human malignant hyperthermia-susceptible muscles via activation of the 
ryanodine receptor Ca2 + channel. Anesthesiology [Internet]. 1996;84:1380-5. Available from: http://www.ncbi.nlm.nih.gov/pubmed/8669679

40. Allen M, Raper S, Mitchell J. Climate change. Uncertainty in the IPCC's Third Assessment Report. Science [Internet]. 2001;293:430-3. Available from: http://www.ncbi.nlm.nih.gov/pubmed/11463898

41. Basu R. High ambient temperature and mortality: a review of epidemiologic studies from 2001 to 2008. Environ Health [Internet]. 2009;8:40. Available from:

http://www.ncbi.nlm.nih.gov/pubmed/19758453

42. Conti S, Masocco M, Meli P, Minelli G, Palummeri E, Solimini R, et al. General and specific mortality among the elderly during the 2003 heat wave in Genoa (Italy). Environ Res [Internet]. 2007;103:26774. Available from: http://www.ncbi.nlm.nih.gov/pubmed/16890219

43. Donaldson GC, Keatinge WR, Saunders RD. Cardiovascular responses to heat stress and their adverse consequences in healthy and vulnerable human populations. Int $\mathrm{J}$ Hyperthermia [Internet]. 2003;19:225-35. Available from: http://www.ncbi.nlm.nih.gov/pubmed/12745969

44. Medina-Ramon M, Zanobetti A, Cavanagh DP, Schwartz J. Extreme temperatures and mortality: assessing effect modification by personal characteristics and specific cause of death in a multi-city case-only analysis. Environ Health Perspect [Internet]. 2006;114:1331-6. Available from: http://www.ncbi.nlm.nih.gov/pubmed/16966084

45. Bark N. Deaths of psychiatric patients during heat waves. Psychiatr Serv [Internet]. 1998;49:108890. Available from: http://www.ncbi.nlm.nih.gov/pubmed/9712220

46. Schifano P, Cappai G, de Sario M, Michelozzi P, Marino C, Bargagli AM, et al. Susceptibility to heat wave-related mortality: a follow-up study of a cohort of elderly in Rome. Environ Health [Internet]. 2009;8:50. Available from: http://www.ncbi.nlm.nih.gov/pubmed/19909505

47. Stafoggia M, Forastiere F, Agostini D, Biggeri A, Bisanti L, Cadum E, et al. Vulnerability to heat-related mortality: a multicity, population-based, case-crossover analysis. Epidemiology [Internet]. 2006;17:315-23. Available from: http://www.ncbi.nlm.nih.gov/pubmed/16570026

48. Schwartz J. Who is sensitive to extremes of temperature?: A case-only analysis. Epidemiology [Internet]. 2005;16:67-72. Available from: http://www.ncbi.nlm.nih.gov/pubmed/15613947

49. Abbott WG, Howard B v, Ruotolo G, Ravussin E. Energy expenditure in humans: effects of dietary fat and carbohydrate. Am J Physiol [Internet]. 1990;258:E347-51. Available from: http://www.ncbi.nlm.nih.gov/pubmed/2305878

50. Thomas CD, Peters JC, Reed GW, Abumrad NN, Sun M, Hill JO. Nutrient balance and energy expenditure during ad libitum feeding of high-fat and high-carbohydrate diets in humans. Am J Clin Nutr [Internet]. 1992;55:934-42. Available from: http://www.ncbi.nlm.nih.gov/pubmed/1570800

51. Tataranni PA, Ravussin E. Effect of fat intake on energy balance. Ann N Y Acad Sci [Internet]. 1997;819:37-43. Available from: http://www.ncbi.nlm.nih.gov/pubmed/9186759

52. Smuder AJ, Kavazis AN, Hudson MB, Nelson WB, Powers SK. Oxidation enhances myofibrillar protein degradation via calpain and caspase-3. Free radical biology \& medicine. 2010;49:1152-60. 
53. Fulle S, Protasi F, di Tano G, Pietrangelo T, Beltramin A, Boncompagni S, et al. The contribution of reactive oxygen species to sarcopenia and muscle ageing. Experimental gerontology. 2004;39:1724.

54. Shigenaga MK, Hagen TM, Ames BN. Oxidative damage and mitochondrial decay in aging. Proceedings of the National Academy of Sciences of the United States of America. 1994;91:107718.

55. Rouben off R, Hughes VA. Sarcopenia: current concepts. The journals of gerontology Series A, Biological sciences and medical sciences. 2000;55:M716-24.

56. Evans WJ. What is sarcopenia? The journals of gerontology Series A, Biological sciences and medical sciences. 1995;50 Spec No:5-8.

\section{Figures}

A

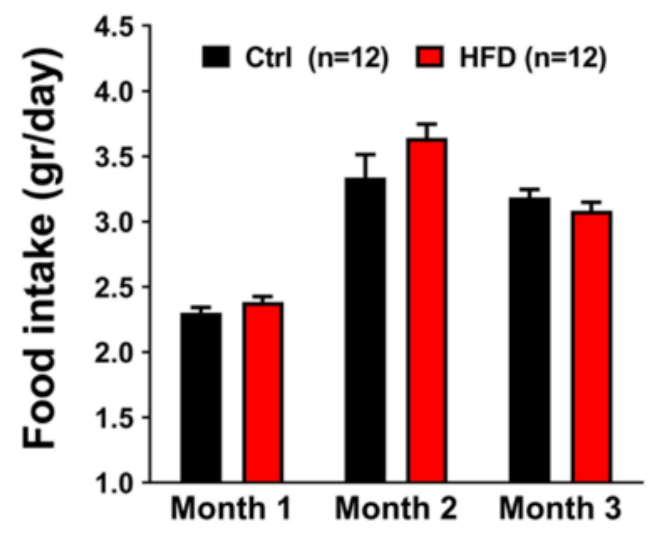

C

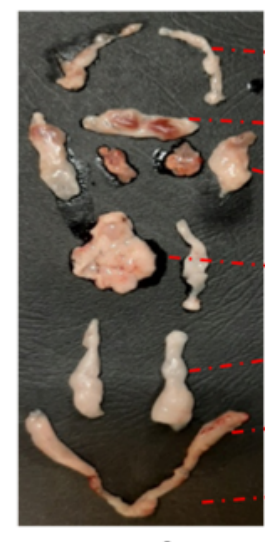

Ctrl
D

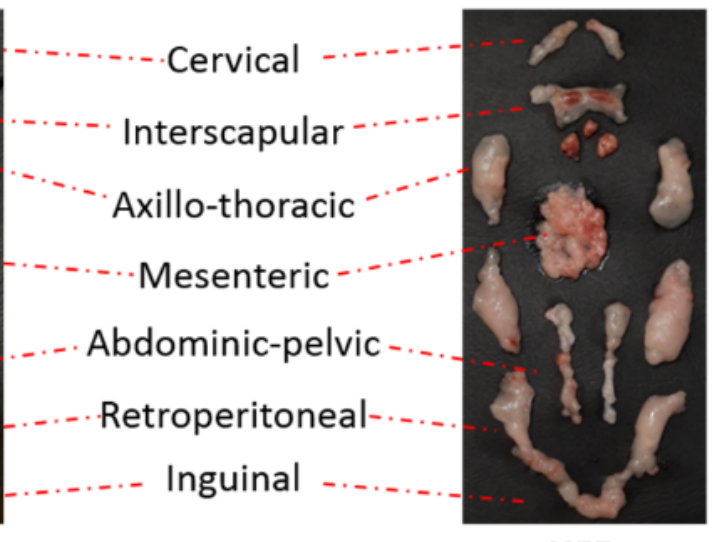

HFD
B

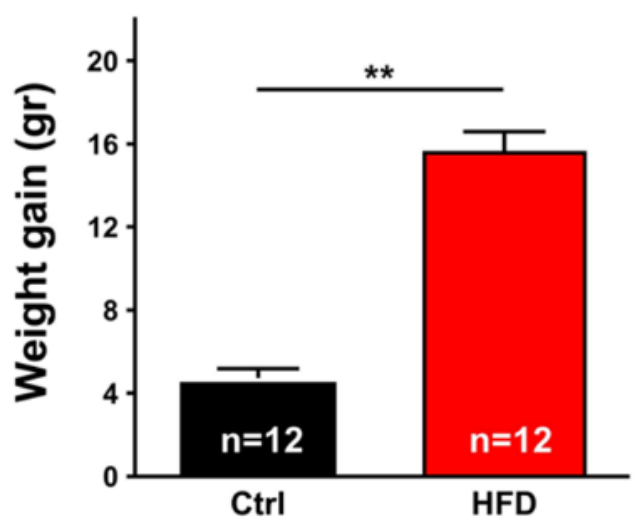

E

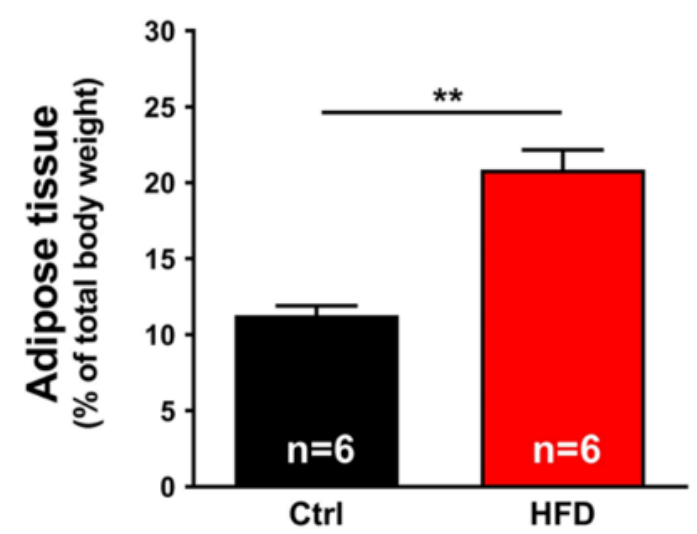

Figure 1 
Food intake, weight gain, and body fat mass. A) Food intake during the 3 months of HFD treatment (1-4 months of age). B) Weight gain during the 3 months of HFD treatment. C) Amount of adipose tissue expressed as percentage of total body weight. $D$ and E) Representative dissection of the total adipose tissue, from Ctrl (D) vs. HFD (E) mice. Data are shown as mean \pm SEM ( $\left.{ }^{\star \star} p<0.01\right)$, as evaluated by twotailed unpaired Student's t-test. $\mathrm{n}=$ number of mice tested.

A

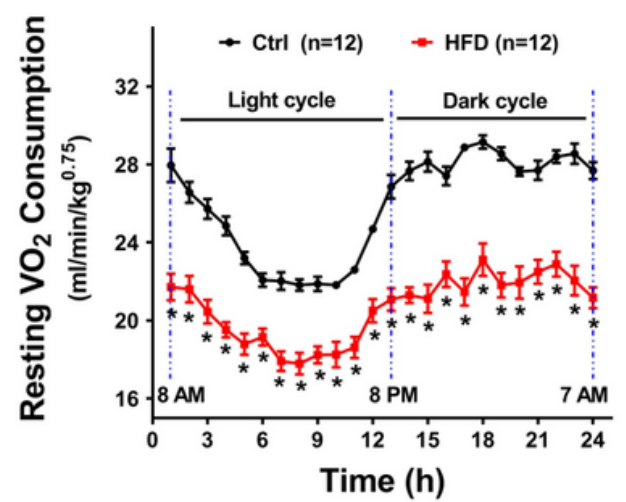

B

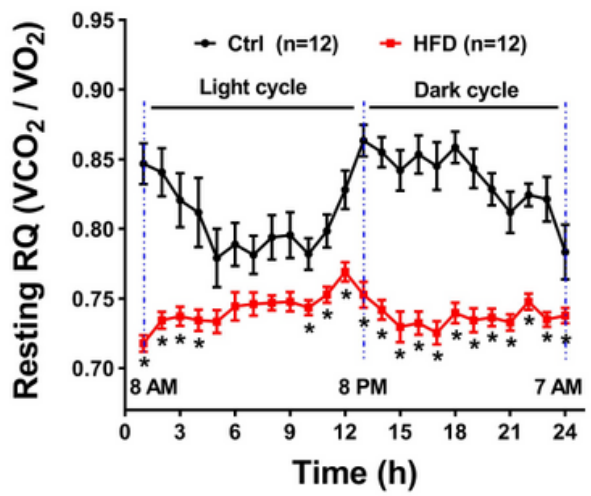

C

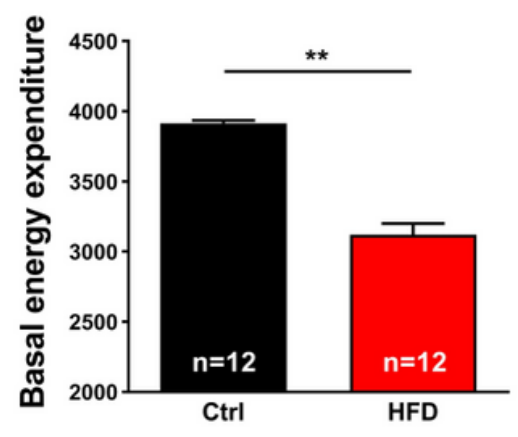

Figure 2

$\mathrm{VO}_{2}$ consumption, respiratory quotient (RQ), and basal energy expenditure during 24 hrs. A) Oxygen consumption expressed as $\mathrm{ml} / \mathrm{min} / \mathrm{kg}^{0.75}$. B) Respiratory quotient expressed as the ratio $\mathrm{VCO}_{2} / \mathrm{VO}_{2}$. C) Area under the curve of $24 \mathrm{hrs}$-basal energy expenditure. Data are shown as mean \pm SEM ( ${ }^{*} p<0.05$ and ${ }^{* *} \mathrm{p}<0.01$ ), as evaluated by two-way ANOVA followed by Tukey's post-hoc test (panels A and B) and twotailed unpaired Student's t-test (panel C). $n=$ number of mice tested.

A

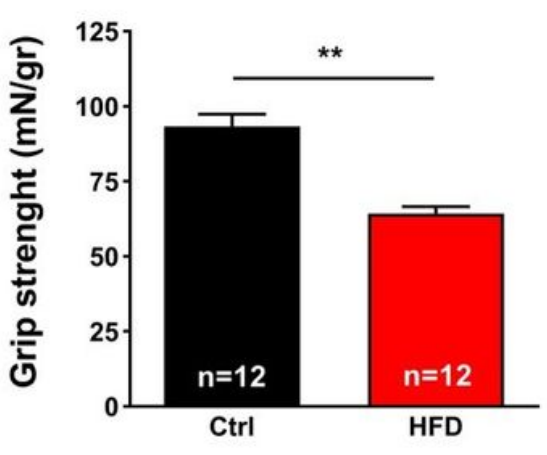

B

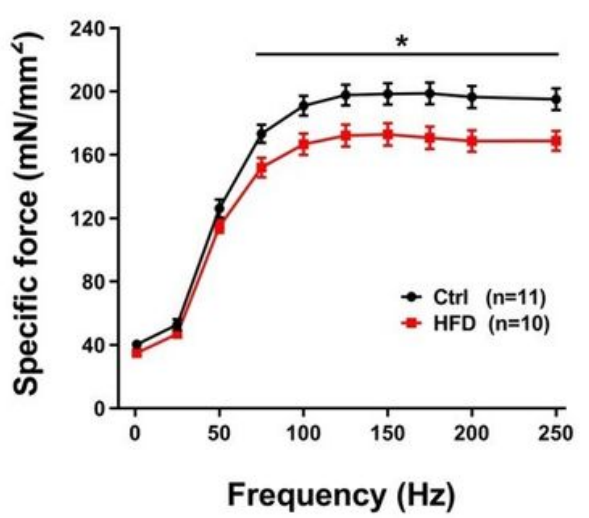

C

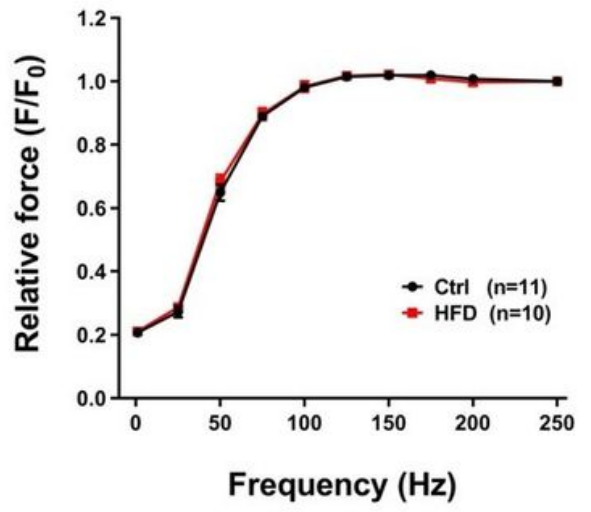

Figure 3 
Grip strength and in vitro specific force. A) Grip strength normalized to body weight (in $\mathrm{mN} / \mathrm{gr}$ ). B and C) Force frequency $(1-250 \mathrm{~Hz})$ curve of specific (panel B) and relative force normalized to $250 \mathrm{~Hz}$ (panel C) in isolated EDL muscles. Data are shown as mean \pm SEM $\left({ }^{*} p<0.05\right)\left({ }^{* \star} p<0.01\right)$, as evaluated by two-way ANOVA followed by Tukey's post-hoc test (panel B) or two-tailed unpaired Student's t-test (panel A). $n=$ number of mice tested in panel $A ; n=$ number of EDL muscles tested (in panels $B$ and $C$ ).

A

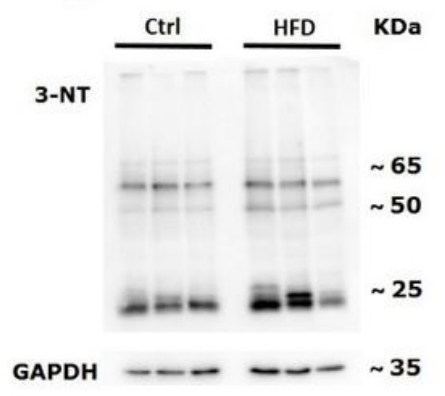

C

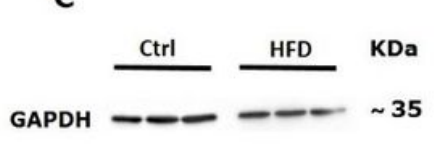

SOD-2 - - - $\sim 23$
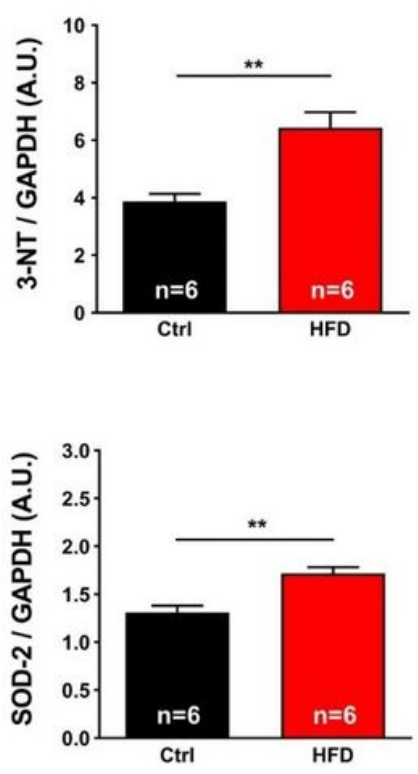

B
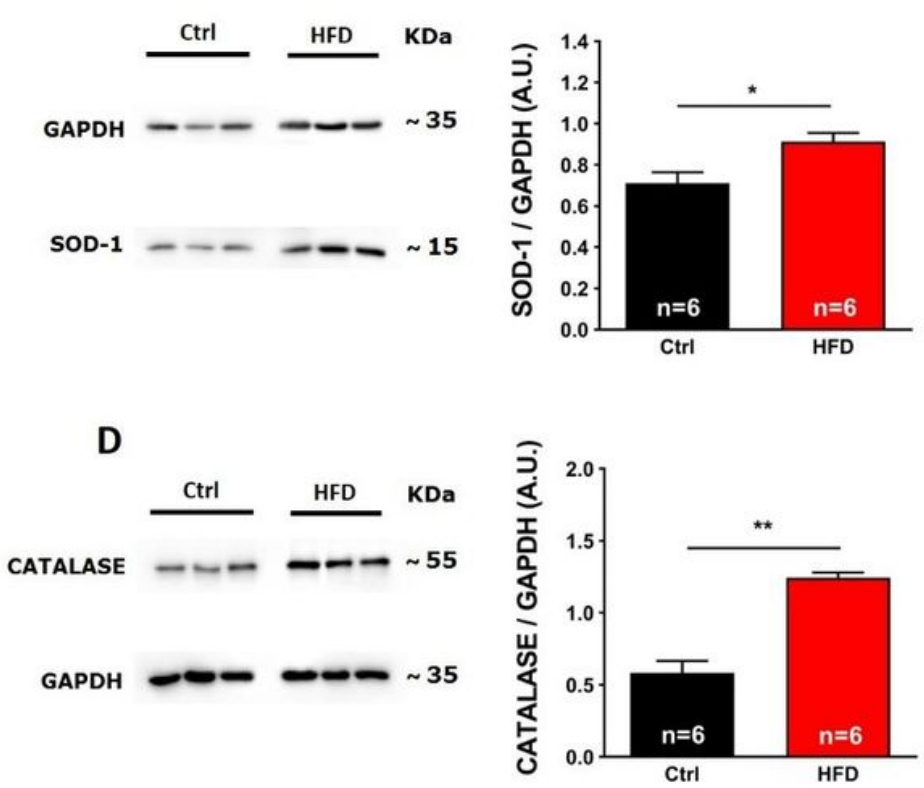

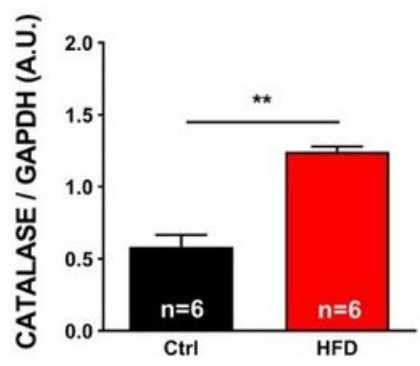

Figure 4

Markers of oxidative stress in EDL muscles. Representative immunoblots (left) and relative band densities normalized to GAPDH levels (right) of 3-NT (panel A), SOD-1 (panel B), SOD-2 (panel C), and Catalase (panel D) in EDL muscle homogenates. Data are shown as mean \pm SEM ( ${ }^{*} p<0.05$ and $\left.{ }^{* *} p<0.01\right)$, as evaluated by two-tailed unpaired Student's t-test. $n=$ number of EDL muscles. 
A

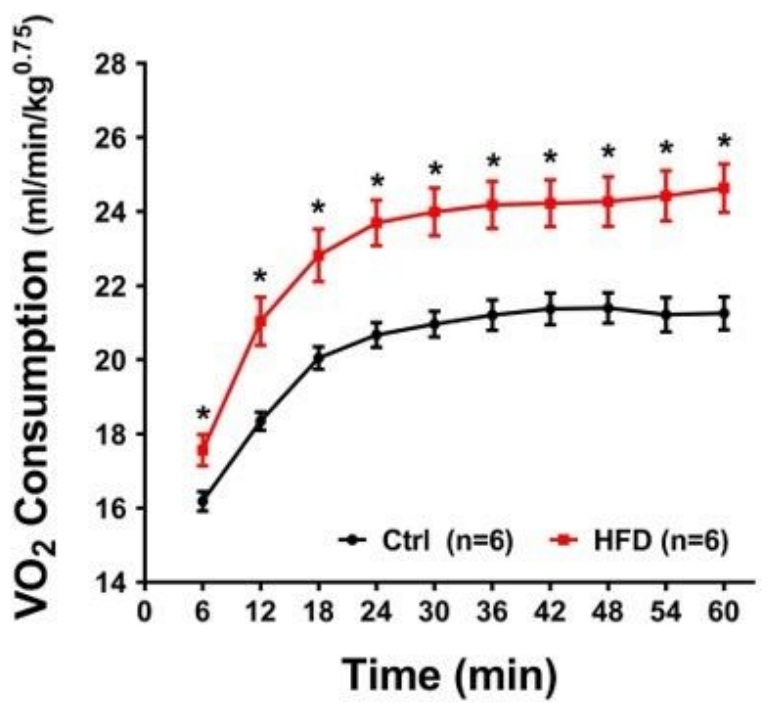

C

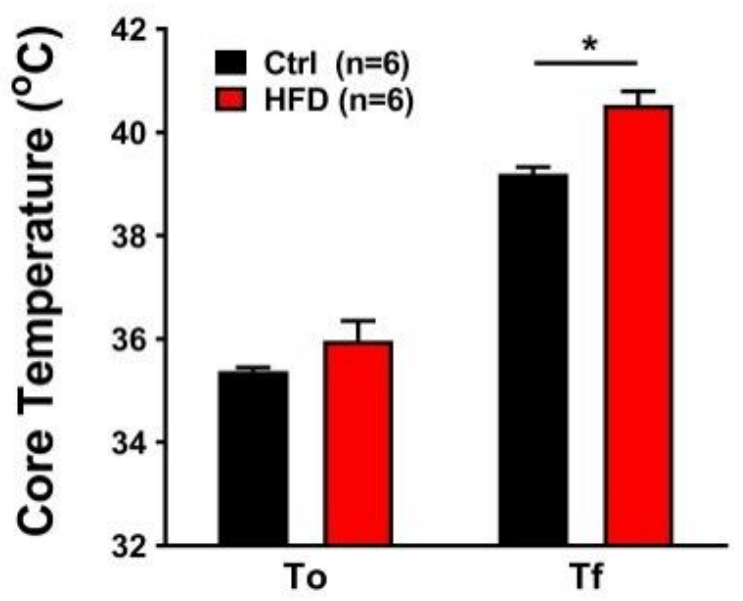

B

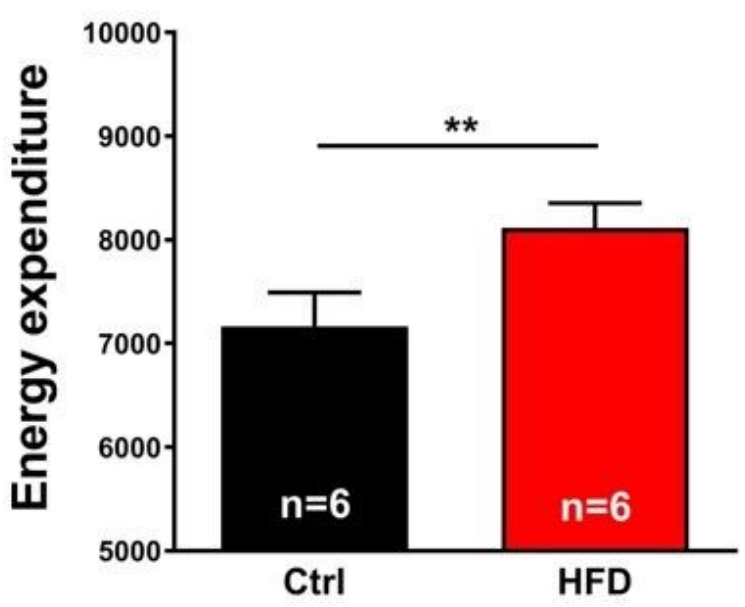

D

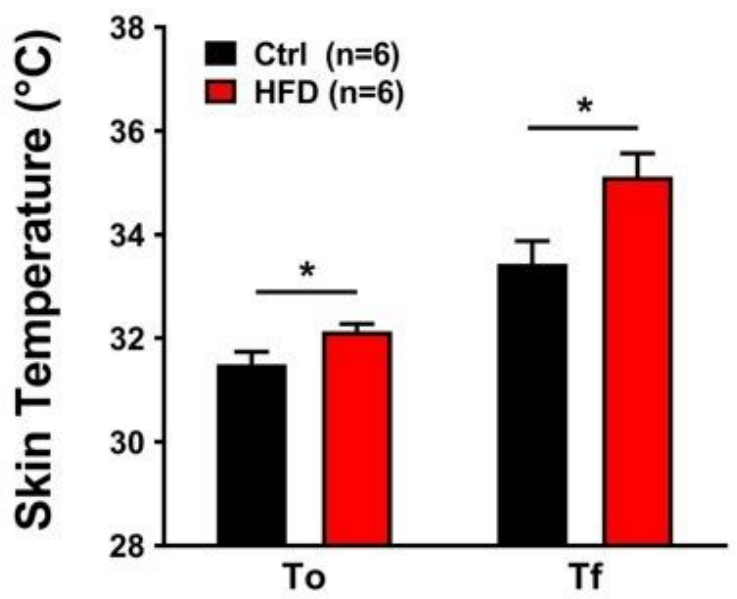

Figure 5

$\mathrm{VO}_{2}$ consumption, energy expenditure, and temperature recorded during $\mathrm{HS}$ protocol ( $41^{\circ} \mathrm{C}$ for $1 \mathrm{hr}$ ). A)

Oxygen consumption expressed as $\mathrm{ml} / \mathrm{min} / \mathrm{kg}^{0.75}$. B) Area under the curve of $60 \mathrm{~min}$-basal energy expenditure. $C$ and $D$ ) Core and skin temperature, immediately before $\left(T_{0}\right)$ and at the end $\left(T_{f}\right)$ the HS protocol. Data are shown as mean \pm SEM $\left({ }^{*} p<0.05\right.$ and $\left.{ }^{*}{ }^{*} p<0.01\right)$, as evaluated by two-way ANOVA followed by Tukey's post-hoc test (panel A) or two-tailed unpaired Student's t-test (panels B-D). $n=$ number of mice tested. 

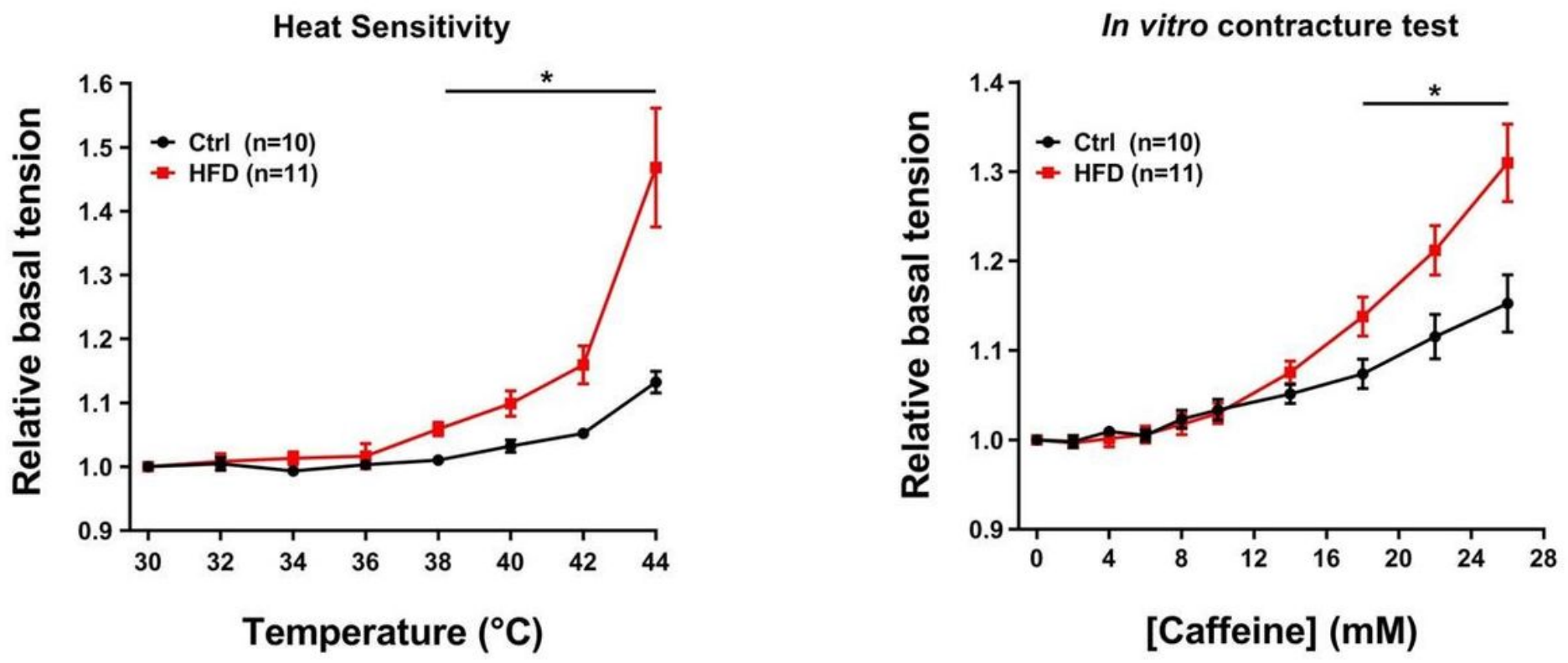

Figure 6

Temperature and caffeine dependence of basal tension in isolated EDL muscles. A) Relative basal tension (normalized to $30^{\circ} \mathrm{C}$ ) during exposure to increasing temperature (from 30 to $44^{\circ} \mathrm{C}$ ). B) Relative basal tension (normalized by $0 \mathrm{mM}$ of caffeine) during exposure to increasing caffeine concentration (from 0 to $24 \mathrm{mM})$. Data are shown as mean \pm SEM $\left({ }^{*} p<0.05\right)$, as evaluated by two-way ANOVA followed by Tukey's post-hoc test. $\mathrm{n}=$ number of EDL muscles tested.

A

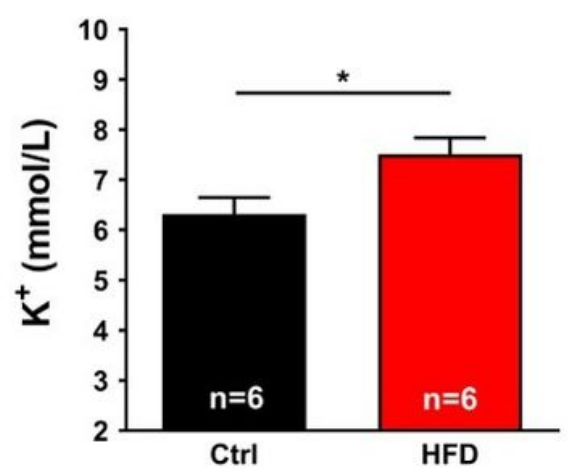

B

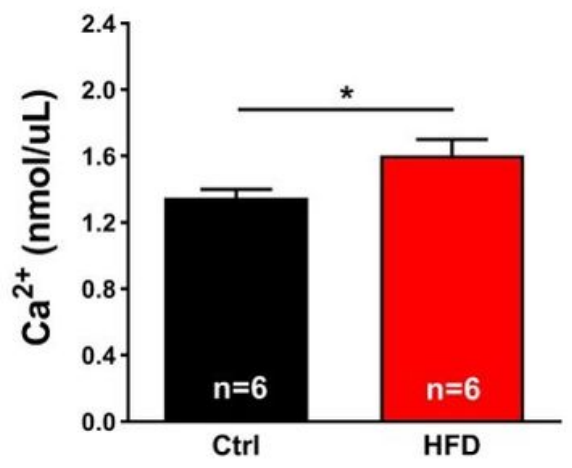

C

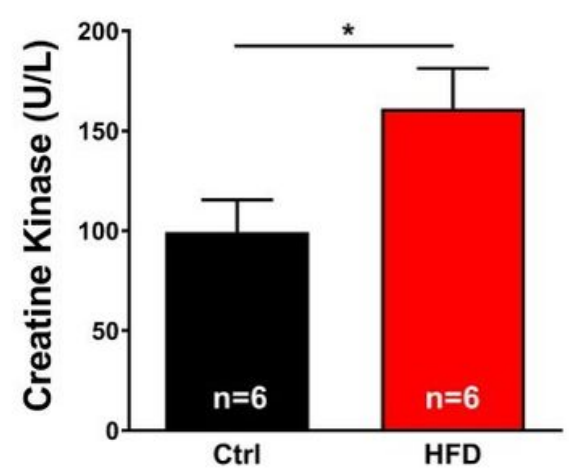

Figure 7 
Blood markers of skeletal muscle damage after the $\mathrm{HS}$ protocol $\left(41^{\circ} \mathrm{C}\right.$ for $\left.1 \mathrm{hr}\right)$. A-C) level of $\mathrm{K}^{+}$in plasma $(\mathrm{mmol} / \mathrm{L})$ (panel A); level of $\mathrm{Ca}^{2+}$ in plasma (nmol/L) (panel B); amount of creatine-kinase $(\mathrm{U} / \mathrm{L})$ in plasma (panel $C)$. Data are shown as mean \pm SEM $\left({ }^{*} p<0.05\right)$, as evaluated by two-tailed unpaired Student 's t-test. $\mathrm{n}=$ number of mice tested.

\section{Supplementary Files}

This is a list of supplementary files associated with this preprint. Click to download.

- SupplementaryMaterial.docx 